\title{
DEVELOPMENT of CAULIS EXTRACT (TINOSPORA CRISPA (L.) HOOK. F. \& THOMSON AS PLASMODIUM IN PREPARATIONS TABLETS
}

\author{
Patimah, Junie Suriawati, Siti Rahayu Rachmawati \\ Jurusan Analisa Farmasi dan Makanan Politeknik Kesehatan Kemenkes Jakarta 2 \\ E-mail: fatimahthamrin66@gmail.com
}

\begin{abstract}
Brotowali (Tinospora crispa (L.) Hook. f. Thomson is a wild plant \& in the Woods, fields or planted page near the fence, and the usual planted as medicinal plants. The entire plant (roots, stems, and leaves) has a bitter taste that can be used as a traditional medicine as Plasmodium. This research aims to make the tablet dosage of Caulis extract with gelatin Binder and polivenilpirolidon materials that meet the requirements of the physical quality of a tablet that is acceptable. Prior to the manufacture of tablets do extract raw materials testing which includes the determination of the levels of ash, determination of microbial impurities, testing the determination of aflatoxin levels of impurities, the determination of the levels of pesticide residues, the determination of the level of heavy metal impurities. Caulis extract tablet manufacture is made with two formula with each different binding materials, namely formula I used gelatin formula II 5\% and 5\% use polivinilpirolidon. The methods used in the manufacture of Caulis extract tablets using a wet granulation method. Granul tested his physical properties obtained covering moist, flow properties, compressibility granule. Tablets obtained physical quality test performed which include uniformity of weight, hardness, size uniformity, compressibility, and the crushed tablets. The data obtained were analyzed statistically using SPSS 15.0 for windows program namely testing T-Test with a $5 \%$ confidence. The results showed that the two formula tablets with the uniformity of weight, hardness, size uniformity, compressibility, and the time crushed tablet that meets the requirements of the physical quality of a good tablet. The conclusions of this research are extracted Caulis tablet can be created that meets the requirements of physical quality test tablet.
\end{abstract}

Keywords: Stem and leaf brotowali, tablet, Wet Granulation.

\section{PENGEMBANGAN EKSTRAK BROTOWALI (TINOSPORA CRISPA (L.) HOOK.F. \& THOMSON SEBAGAI ANTI PLASMODIUM DALAM SEDIAAN TABLET}

\begin{abstract}
ABSTRAK
Brotowali (Tinospora crispa (L.) Hook.f.\& Thomson merupakan tumbuhan liar di hutan, ladang atau ditanam dihalaman dekat pagar, dan biasa ditanam sebagai tumbuhan obat. Seluruh tanaman ini (batang, akar, dan daun) mempunyai rasa pahit yang dapat digunakan sebagai obat tradisional sebagai anti plasmodium. Penelitian ini bertujuan untuk membuat sediaan tablet dari ekstrak brotowali dengan bahan pengikat gelatin dan polivenilpirolidon yang memenuhi persyaratan mutu fisik tablet yang dapat diterima. Sebelum dilakukan pembuatan tablet dilakukan pengujian bahan baku ekstrak yang meliputi penetapan kadar abu, uji cemaran mikroba, cemaran aflatoksin, residu pestisida, cemaran logam berat. Pembuatan tablet ekstrak brotowali ini dibuat dengan dua formula dengan masing-masing bahan pengikat yang berbeda yaitu formula I menggunakan gelatin 5\% dan formula II menggunakan polivinilpirolidon 5\%. Metode yang digunakan dalam pembuatan tablet ektrak brotowali menggunakan metode granulasi basah. Granul yang diperoleh diuji sifat fisiknya yang meliputi kadar lembab, sifat alir, kompresibilitas granul. Tablet yang diperoleh dilakukan uji mutu fisik yang meliputi keseragaman bobot, keseragaman ukuran, kekerasan, kompresibilitas, dan waktu hancur tablet. Data yang diperoleh dianalisa secara statistik den gan menggunakan program SPSS 15.0 for windows yaitu uji T-Test dengan kepercayaan 95\%. Hasil penelitian menunjukkan bahwa dua formula tablet dengan keseragaman bobot, keseragaman ukuran, kekerasan, kompresibilitas, dan waktu hancur tablet yang memenuhi persyaratan mutu fisik tablet yang baik. Kesimpulan bahwa ektrak brotowali dapat dibuat tablet yang memenuhi persyaratan uji mutu fisik tablet.
\end{abstract}

Kata kunci : Batang dan daun brotowali, tablet, granulasi bas 


\section{PENDAHULUAN}

Malaria masih merupakan salah satu masalah kesehatan masyarakat yang dapat menyebabkan kematian terutama pada kelompok resiko tinggi yaitu bayi, anak balita, ibu hamil, dan selain itu malaria juga menurunkan produktivitas kerja. Dibeberapa negara di dunia, terutama di bagian belahan Afrika dan Asia Tenggara, termasuk Indonesia, penyakit malaria terutama malaria falciparum masih merupakan masalah besar yang merupakan salah satu penyebab tingginya angka kematian, sehingga diperkirakan 100 juta kasus penyakit malaria terjadi setiap tahunnya dengan $1 \%$ diantaranya meninggal, sedangkan di Indonesia diperkirakan 15 juta penduduk menderita malaria dengan 38 ribu meninggal dunia setiap tahunnya (1).

Penggunaan sediaan obat bahan alam semakin populer, karena kepedulian masyarakat terhadap obat herbal yang lebih dikenal dengan obat tradisional semakin meningkat. Hal ini terutama disebabkan harganya yang relatif terjangkau, mudah diperoleh dan juga sediaan obat bahan alam relatif aman serta memiliki efek samping yang minimal (2).
Brotowali (Tinospora crispa) merupakan tumbuhan liar di hutan, ladang atau ditanam dihalaman dekat pagar, dan biasa ditanam sebagai tumbuhan obat. Seluruh tanaman ini (batang, akar, dan daun) mempunyai rasa pahit yang disebabkan oleh beberapa senyawa seperti kolumbin, alkaloid, glukosida, pikroretin, dan berberin (3).

Secara umum di dalam tanaman brotowali (Tinospora crispa) terkandung berbagai senyawa kimia antara lain alkaloid. Damar lunak, pati, glikosida, pikroretosid, berberin, palmatin, kolumbin, pikroretin, tinokrisposid, dan kaolin atau pikrotoksin. Senyawa aktif dalam batang brotowali yang berfungsi sebagai antimalaria adalah tinokrisposid yang dapat bekerja di fase eritrositer dengan cara menghambat parasit dalam eritrosit. Pemberian ekstrak batang tinospora crispa mampu menurunkan anemia dengan mencegah hemolisis eritrosit melalui mekanisme non imun, ekstrak batang brotowali (Tinospora crispa) dapat menekan perkembangan Plasmodium berghei dalam darah mencit sehingga tidak terjadi sporulasi. Hal ini didukung dengan adanya penelitian sebelumnya yang telah dapat 
membuktikan bahwa senyawa tinokrisposid yang terdapat pada batang brotowali (Tinospora crispa) mampu menekan perkembangan Plasmodium berghei dalam darah mencit dan memperpanjang hidup mencit yang terinfeksi dengan dosis $400 \mathrm{mg} / \mathrm{kg}$ BB.(4).

Ihwan et al telah melaporkan hasil penelitiannya bahwa ekstrak batang Tinospora crispa setelah diinkubasi selama 48 dan 72 jam memiliki aktivitas anti plasmodium dengan nilai IC50 sebesar $0,29 \mathrm{mg} / \mathrm{ml}$ dan $0,27 \mathrm{mg} / \mathrm{ml}$ dan dosis efektif untuk menghambat pertumbuhan Plasmodium Falciparum galur 3D7 adalah 2,0 mg/ml dengan menurunkan derajat parasetemia sebesar 47,12\% dan 56,83\% setelah inkubasi 72 jam.(5)

Lumowa telah melaporkan hasil penelitiannya bahwa ekstrak etanol batang brotowali memberikan hambatan terhadap pertumbuhan Plasmodium berghei dengan ED50 sebesar 3,57197 $\mathrm{mg} / \mathrm{kg}$ BB.(6)

Dengan didukung oleh banyak penelitian yang membuktikan khasiat ekstrak dari berbagai tumbuhan yang memiliki aktivitas sebagai anti plasmodium, maka pada penelitian ini ingin mengembangkan ekstrak brotowali yang memiliki aktivitas sebagai antiplasmodium yang kemungkinan kalau ada dipasaran masih dalam bentuk kapsul, maka dari itu akan dibuat sediaan tablet dengan zat pengikat gelatin dan polivilpirolidon (PVP) untuk mengetahui daya ikat pada ekstrak brotowali dengan formula yang sesuai dengan uji parameter sediaan tablet.

Penelitian ini bertujuan Untuk mengetahui pengaruh bahan pengikat terhadap sifat fisik tablet ekstrak brotowali, memperoleh formula dengan membandingkan bahan pengikat gelatin dan polivinilpirolidon (PVP) yang dapat memberikan sifat fisik tablet yang optimum pada formulasi tablet ekstrak brotowali. Dan Manfaat Penelitian digunakan sebagai pengembangan pemanfaatan ekstrak brotowali sebagai obat tradisional yang dikemas dalam bentuk sediaan yang lebih modern yaitu tablet, penggunakan bahan pengikat gelatin dan polivinilpirolidon (PVP) diharapkan dapat mengasilkan sediaan tablet yang baik.

\section{METODE PENELITIAN}

\section{Alat dan Bahan}

Alat adalah timbangan digital, mesin cetak tablet single punch, pengayak, 
jangka sorong, hardnes tester (merck Kraemer Gmbh), bulk density tester (merck copley), disintegration tester (merck veego), friability testes (merck charles ischi AG), oven (marmert), water bath, rotari evaporator, dan peralatan gelas.

Bahan adalah ekstrak brorowali, libermen bouchardat, mayer, HCL, $\mathrm{FeCl} 3, \mathrm{HCL} 2 \mathrm{~N}, \mathrm{H} 2 \mathrm{SO} 4$, etanol 95\%, toluen, dietil eter, asam asetat, metanol, kloroform, aguabides, etil asetat, asam asetat, ammonia, norit, bahan pembuatan tablet sepertiavicel $\mathrm{pH} 101$, gelatin, polivinilpirolidon/PVC, laktosa, nipagin, magnesium stearate, talkum, aerosil, starch 1500.

\section{Prosedur}

\section{a. Penapisan Fitokimia Ekstrak Brotowali.}

Penapisan fito kimia yang dilakukan untuk mengetahui kandungan metabolit sekunder yang terdapat dalam ekstrak (7).

\section{b. Pemeriksaan Uji Mutu Bahan}

\section{Baku Ekstrak Brotowali.}

Pemeriksaan Uji Mutu Bahan Baku Ekstrak Brotowali dilakukan dengan penetapan kadar abu, Uji Cemaran Mikroba terhadap Angka Lempeng Total (ALT) dan Angka Kapang dan Kamir (AKK). Penetapan cemaran Aflatoksin, Penetapan residu pestisida, Cemaran logam berat (8).

\section{c. Pembuatan massa cetak tablet dan evaluasi}

Formula tablet dibuat dengan bobot sesuai dosis per tablet, dengan metode granulasi basah karena metode ini yang

Tabel 1. Formulasi Tablet secara Granulasi Basah Dengan bahan pengikat gelatin $5 \%$ dan polivinilpirolidon $5 \%$

\begin{tabular}{lccl}
\hline \multicolumn{1}{c}{ Nama Bahan } & Formulasi 1 & Formulasi 2 & Jenis fase \\
\hline Ekstrak Brotowali & $400 \mathrm{mg}$ & $400 \mathrm{mg}$ & \\
Avicel pH 101 & $10 \%$ & $10 \%$ & \\
Gelatin & $5 \%$ & - & \\
Polivinilpirolidon & - & $5 \%$ & Fase Dalam \\
Nipagin & $0,1 \%$ & $0,1 \%$ & \\
Mg Stearat & $1 \%$ & $1 \%$ & \\
Laktosa & $\mathrm{Qs}$ & $\mathrm{Qs}$ & \\
\hline Talkum & $1 \%$ & $1 \%$ & \\
Aerosil & $0,5 \%$ & $0,5 \%$ & FaseLuar \\
Starch & $5 \%$ & $5 \%$ & \\
\hline
\end{tabular}


paling umum dipilih dengan pertimbangan mudah dalam pengerjaannya. Perhitungan dosis dihitung berdasarkan pengujian aktivitas antiplasmodium menggunakan perhitungan ED50 dari hasil penelitian yang sudah pernah dilakukan sesuai jurnal wijaya kusuma volume1 nomor 1 Januari 2007 sebesar 400 mg. Sebagai bahan pengisi (filler) tablet fase dalam digunakan avicel pH 101 dan laktosa, dan untuk bahan pengikat (binder) digunakan gelatin, polivinilpirolidon (PVP) dipilih gelatin dan polivinilpirolidon ingin mengetahui daya ikat dengan membandingkan pengikat alami dengan pengikat sintetik.(9) Komposisi tablet yang akan dibuat adalah pada Tabel 1

Setelah tablet selesai dicetak dilakukan evaluasi terhadap tablet sebagai berikut:

\section{a. Evaluasi fisik granul}

Evaluasi fisik granul dilakukan dengan menetapkan kadar lembab granul, Sifat alir granul, kompresibilitas granul.(10,11)

\section{b. Pencetakan tablet}

Setelah dilakukan evaluasi granul kemudian ditimbang bobot granul yang diperoleh, kemudian dilakukan perhitungan jumlah masing-masing bahan yang akan dicetak sesuai dengan perhitungan, dan dilakukan evaluasi tablet.

\section{c. Evaluasi tablet}

Evaluasi tablet dilakukan terhadap keseragaman bobot tablet, keseragaman ukuran tablet, kekerasan tablet, kerenyahan tablet, keseragaman kandungan tablet, dan waktu hancur tablet.(10,12,13)

Tabel 2 Hasil Penapisan Fitokimia

\begin{tabular}{llll}
\hline \multicolumn{1}{c}{ UJI } & \multicolumn{1}{c}{ PEREAKSI } & \multicolumn{1}{c}{ PERSYARATAN } & HASIL \\
PENAPISAN & & Merah & Merah kehijauan \\
Alkaloid & Wagner & Kayer & Cokelat kekuningan \\
& Dragendorf & Cokelat & Cokelat kehijauan \\
Steroid & Asama setan dan asam & Perubahan warna biru & Biru kehijauan \\
& Sulfat & Atau hijau & \\
Triterpenoid & Kloroform dan asam sulfat & $\begin{array}{l}\text { Perubahan warna } \\
\text { Merah kecokelatan }\end{array}$ & Cokelat kemerahan \\
Glikosida & Asam asetat glasia ldan & Cincin cokelat & Cincin cokelat \\
& $\mathrm{FeCl} 3+$ H2SO4 & Kuning & Kuning \\
Flavonoid & $\mathrm{NaOH}$ & Buih & Buih \\
Saponin & $\mathrm{HCl} 2 \mathrm{~N}$ & Biru kehijauan & Biru kehijauan \\
Fenol & $\mathrm{FeCl} 3$ & Hijau & Hijau \\
Tanin & $\mathrm{FeCl} 3$ & & \\
\hline
\end{tabular}




\section{HASIL DAN PEMBAHASAN}

\section{Penapisan Fitokimia Ekstrak}

Brotowali.

Hasil penapisan fitokimia ekstrak brotowali dinyatakan positif karena sesuai dengan persyaratan seperti pada Tabel 2.

\section{Pemeriksaan Uji Mutu Bahan Baku}

Ekstrak Brotowali.

a. Penetapan Kadar Abu

Pengujian kadar abu dilakukan tiga kali, hasil pengujian kadar abu ekstrak brotowali sebesar 0,0395 mg

\section{b. Uji Cemaran Mikroba}

Pemeriksaan cemaran mikroba digunakan untuk menjamin bahwa ekstrak tidak mengandung mikroba patogen dan non patogen yang berbahaya bagi kesehatan. Hasil pengujian cemaran mikroba Angka Lempeng Total dan Angka Kapang Khamir menunjukkan hasil yang negatif.

\section{c. Penetapan Residu Pestisida}

Pemeriksaan residu pestisida dilakukan menggunakan metode Kromatografi Gas. Hasil pemeriksaan menunjukkan bahwa ekstrak brotowali negatif tidak mengandung residu pestisida sehingga dinyatakan memenuhi syarat.

\section{d. Penetapan Cemaran Aflatoksin}

Hasil penetapan tingkat cemaran aflatoksin secara kuantitatif dilakukan secara Kromatografi Cair Kinerja Tinggi (KCKT), hasil pemeriksaan cemaran aflatoksin yaitu negatif sehingga memenuhi syarat terhadap persyaratan.

\section{e. Cemaran Logam Berat}

Pemeriksaan cemaran logam berat $\mathrm{Pb}, \mathrm{Cd}, \mathrm{Hg}$, dan As, masih dibawah batas limit deteksi. Limit deteksi yang dipersyaratkan yaitu untuk $\mathrm{Pb}$ $\leq 10$ ppm, $\mathrm{Cd} \leq 0,3$ ppm, $\mathrm{Hg} \leq 0,5$ ppm, dan As $\leq 5$ ppm. Jadi hasil masih memenuhi syarat, yaitu untuk $\mathrm{Pb}=0,0013, \mathrm{Cd}=0,0003$, $\mathrm{Hg}=0.1200$, dan As $=0,0021$.

\section{Pembuatan Masa Cetak Tablet dan}

\section{Evaluasi}

a. Evaluasi Granul

1) Penetapan kandungan lembab granul

Tuuan dilakukan uji ini adalah untuk mengetahui kandungan lembab granul karena kelembaban yang terlalu tinggi akan mempengaruhi kekerasan tablet. 
Hasil pemeriksaan kandungan lembab granul memenuhi syarat jika kadar air untuk granul sebagai massa siap cetak adalah $3-5 \%$. Hasil perhitungan didapat kadar rata - rata dengan bahan pengikat gelatin $5 \%$ sebesar $3,52 \% \pm$ 0,30 dan kadar rata-rata dengan bahan pengikat polivinilpirolidon $5 \%$ sebesar $3,97 \% \pm 0,02$ menunjukkan hasil yang memenuhi syarat kadar lembab granul, Setelah dilakukan perhitungan secara statistik terdapat perbedaan bermakna $(p<0,05)$ karena pengikat gelatin sewaktu dipanaskan agak lama kering bila dibandingkan dengan polivinilpirolidon.

2) Penetapan sifat alir granul

Sifat alir granul didalam persyaratan dinyatakan setiap 100 gram granul waktu alirnya tidak lebih dari 10 detik. Sifat alir granul yang baik

Tablet dengan bahan pengikat Gelatin 5\%

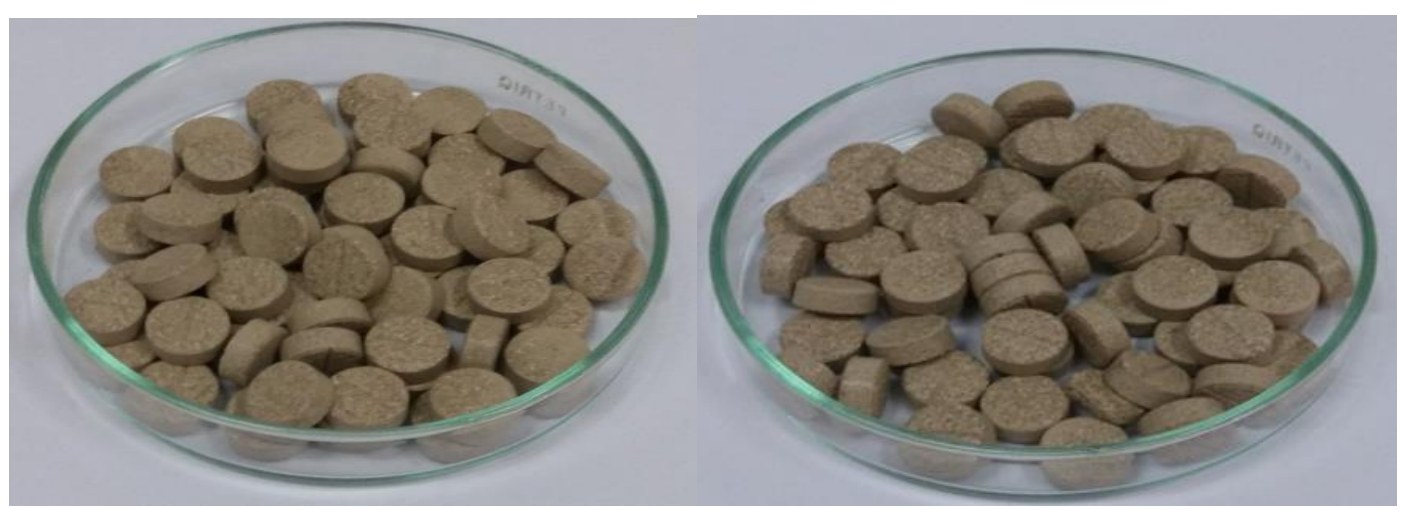

menyebabkan pengisian ke dalam ruang kompresi akan selalu konstan sehingga berat tablet akan konstan dan kandungan zat aktif juga akan seragam. Hasil penetapan sifat alir granul dilakukan tiga kali pengujian menunjukan hasil rata rata dengan bahan pengikat gelatin 5\% sebesar 2,05 $\pm 0,02$ dan pengikat polivinilpirolidon $5 \%$ hasil rata rata sebesar $1,48 \pm$ 0,01,lebih cepat sifat alir polivinilpirolidon $5 \%$ bila dibandingkan dengan gelatin 5\%. Hasil memenuhi syarat tidak lebih dari 2,5 detik karena granul yang digunakan 25 gram. Hasil perhitungan statistik T-test menunjukkan tidak adanya perbedaan bermakna $(\mathrm{p}<0,05)$ antara pengikat gelatin 5\% dengan polivinilpirolidon $5 \%$.

3) Penetapan Kompresibilitas Granul
Tablet dengan bahan pengikat polivinilpirolidon $\mathbf{5 \%}$

Gambar 1 : Tablet dengan pengikat Gelatin 5\% dan Polivinilpirolidon 5\% 
Kemampatan diuji untuk mengetahui sifat alir granul, dan hasil memenuhi persyaratan yaitu kemampatan yang baik adalah $<20 \%$ Hal ini menunjukkan penggunaan bahan pengikat Gelatin dan povinilpirolidon dapat digunakan bahan pengikat dan bisa juga sekaligus sebagai bahan pengisi pembuatan tablet.

\section{b. Pencetakan tablet}

Setelah dilakukan evaluasi granul dilakukan pencetakan tablet (Gambar 1). Hasil pencetakan tablet yang dilakukan dengan masing-masing formulasi dengan menggunakan bahan pengikat gelatin $5 \%$ dan polivinilpirolidon $5 \%$.

\section{Evaluasi Tablet}

Pemeriksaan uji mutu fisik tablet dilakukan untuk mengetahui apakah tablet yang sudah dibuat memenuhi persyaratan Farmakope Indonesia dan pustaka lain, sehingga diharapkan dapat menghasilkan mutu tablet yang baik. Pemeriksaan mutu fisik tablet meliputi keseragaman bobot, ukuran, kekerasan, kerenyahan, dan waktu hancur tablet.

\section{Penetapan Keseragaman Bobot Tablet}

Keseragaman bobot dipengaruhi oleh sifat alir granul. Sifat alir granul yang baik mempengaruhi pengisian pada ruang kompresi dengan volume konstan sehingga diperoleh tablet yang bobotnya seragam. Berdasarkan persyaratan di Farmakope Indonesia masih memenuhi persyaratan untuk tablet dengan bobot lebih besar $300 \mathrm{mg}$ bobot rata rata tidak boleh menyimpang dari $5 \%$, dan tidak boleh satu tabletpun yang bobotnya menyimpang dari bobot rata-rata lebih besar dari 10\%.(12) Hasil perhitungan didapat $1,8 \%$. Pemeriksan keseragaman bobot tablet dilakukan terhadap 20 tablet dengan menimbang satu per satu dan dibuat rata - rata bahan pengikat gelatin $5 \%$ sebesar $667,5 \mathrm{mg} \pm 15,85$ dan pengikat polivinilpirolidon $5 \%$ rata rata 654,5 $\mathrm{mg} \pm 16,05$, Hasil perhitungan secara statistik T-test tidak ada perbedaan yang bermakna $(\mathrm{p}<0,05)$ dengan tingkat homogenitas 0,729 .

\section{Penetapan Keseragaman Ukuran}

Diameter tablet tidak boleh lebih dari 3 kali ketebalan tablet dan tidak kurang dari 4/3 kali tebal tablet.(12) Hasil pengukuran ketebalan dan diameter tablet dengan bahan pengikat gelatin 5\% didapat hasil rata-rata 4,28 $\mathrm{mm} \pm 0,10$ dan polivinilpirolidon $5 \%$ didapat hasil rata-rata $4,24 \mathrm{~mm} \pm 0,13$. 
Hasil tidak memenuhi persyaratan karena melebihi persyaratan. Hasil perhitungan statistik ada perbedaan bermakna $(\mathrm{p}<0,05)$.

\section{Penetapan Kekerasan Tablet}

Kekerasan tablet berpengaruh terhadap daya hancur serta kecepatan melarut obat, kekerasan tablet yang cukup serta tahan penyerbukan dan kerenyahan merupakan persyaratan penting bagi penerimaan konsumen, menurut Ansel kekerasan untuk tablet yang baik adalah $4-10 \mathrm{~kg} / \mathrm{cm} 2 .(10)$ Hasil dengan bahan pengikat gelatin 5\% sebesar 4,92 kg/cm2 $\pm 0,69$ dan bahan pengikat polivinilpirolidon $5 \%$ sebesar $6,02 \mathrm{~kg} / \mathrm{cm} 2 \pm 0,66$ dan masih memenuhi persyaratan. Hasil secara statistik tidak ada perbedaan yang bermakna $(\mathrm{p}<0,05)$ antara bahan pengikat gelatin 5\% dengan bahan pengikat polivinilpirolidon $5 \%$.

\section{Penetapan Kerenyahan Tablet}

Pengujian kerenyahan tablet dilakukan untuk mengetahui kekuatan tablet terhadap goncangan atau gangguan mekanik pada saat pengemasan hingga pengangkutan dan sampai ke konsumen. Pengujian dilakukan sebanyak 20 tablet dibersihkan dari serbuk halus dimasukkan kedalam alat friabilator dan diputar 100 putaran, didapat hasil untuk bahan pengikat gelatin $5 \%$ sebesar $0,43 \%$ dan bahan pengikat polivinilpirolidon $5 \%$ sebesar $0,72 \%$ dan hasil memenuhi persyaratan yaitu dinyatakan baik jika $<1 \%$, jika $>1 \%$ tablet dapat diperbaiki dengan cara meningkatkan kekerasan tablet.

\section{Penetapan Waktu Hancur Tablet}

Persyaratan waktu hancur tablet adalah $\mathrm{t}<$ dari 15 menit. Hasil pengujian tablet dengan bahan pengikat gelatin 5\% sebesar 4 menit 37 detik \pm 0,02 dan bahan pengikat polivinilpirolidon $5 \%$ sebesar 3 menit 33 detik $\pm 0,07$ dan masih memenuhi persyaratan.

\section{SIMPULAN}

Hasil pengujian penapisan fitokimia, mutu bahan baku dan sifat fisik granul ekstrak memenuhi persyaratan. Untuk kadar lembab ada perbedaan bermakna antara bahan pengikat gelatin 5\% dengan bahan pengikat polivinilpirolidon $5 \%$ bahan pengikat gelatin agak lama waktu pengeringannya. 


\section{UCAPAN TERIMA KASIH}

Direktur Piliteknik Kesehatan Jakarta II Kementerian Kesehatan RI Nomor HK.00.05./I/4822/2016.

\section{DAFTAR PUSTAKA}

1. Departemen Kesehatan Republik Indonesia. Pedoman Penatalaksaan Kasus Malaria di Indonesia. Jakarta : Direktorat Jenderal Pengendalian Penyakit dan Penyehatan Lingkungan; 2006. P. 3-14.

2. Badan Pengawasan Obat dan Makanan Republik Indonesia. Pedoman Teknologi Formulasi Sediaan Berbasis Ekstrak Volume 2. Jakarta;2013.

3. Badan Pengawasan Obat dan Makanan Republik Indonesia. Monografi Ekstrak Tumbuhan Obat Indonesia. Vol. 2 ;2006. P. 22-27

4. Suryawati, $\mathrm{S}$ dan Herni. Efek Antimalaria ekstrak Brotowali (Tinospora crispa) pada mencit yang diinfeksiPlasmodium berghei. Wijaya Kusuma I(1);2007. p.13-22.

5. Ihwan.,Muhaimin Rifa., Fitri LE. Uji Anti Plasmodium Ekstrak Batang Tinospora crispa terhadap Plasmodium falciparum Galur 3 D7 secara In Vitro. Kupang Nusa Tenggara Timur, Jurnal Kedokteran Brawijaya;2014.

6. Lumowa D., Antimalaria Ekstrak Etanol Batang Brotowali (Tinospora Crispa Diels) Secara In Vivo. Universitas Surabaya;2008.

7. Departemen Kesehatan Republik Indonesia. Parameter Standar Umum Ekstrak Tumbuhan Obat. Direktorat Jenderal Pengawasan Obat dan Makanan; 2000. P. 3-65
8. Departemen Kesehatan Republik Indonesia. Sediaan Galenik. Direktorat Jenderal Pengawasan Obat dan Makanan;1986. P. 10-16

9. Lachman L., Lieberman A.H, Kanig L.J. Pharmaceutical Dosage Forms : Tablets, Volume 1, Edisi kedua. New York: Marcel Dekker Inc., 1994. P. 114, 115, 121, 137, $148,163,543-583$, 643-715, 15141602.

10. Siregar Charles IP.Teknologi Farmasi Dasar-dasar praktis sediaan tablet, Jakarta ; EGC ;2010. p. 301 - 364.

11. Ansel, H.C., Pengantar Bentuk Sediaan Farmasi, Edisi keempat. Diterjemahkan oleh Soedani N.S. dkk Yogyakarta : Gadjah Mada University Press; 1989. P. 201-300

12. Voigt R. Buku Pelajaran Teknologi Farmasi. Edisi kelima. Diterjemahkan oleh Soendani N.S., dkk. Yogjakarta: Gajah Mada University Press. 1995. p. 165 213.

13. Rowe, Raymond C., Paul J. Sheskey, Paul J. Weller, Handbook of Pharmaceutical Excipient, Washington: Pharmaceutical express and American Pharmaceutical Association; 2003. p. 596-599 